\title{
OBEmanager: a model of OBE mobile application system management for the academician
}

\begin{abstract}
Outcome-based Education (OBE) right now is very important to the academician, especially in Higher learning Institutions (HLI) in ensuring the student will get the benefits in teaching and learning of their study. In this context, there is a lacking of the OBE system model in helping the academician to use in OBE management for mobile application system environment. Since that, the implementation of the OBE as a system model for mobile application called as OBEmanager which main objectives is to offer the academician and easy and straightforward access to general information about their courses. So that it's easy to monitor the OBE of student achievement based on Cognitive, Psychomotor and Affective (CPA). Therefore, in this paper we will be highlighting a system model of OBE for academician in HLI. The proposed model will be covering the conceptual design and its interaction as well as the system configuration in supporting the academician to use it in their teaching and learning towards effectiveness and its efficiency.
\end{abstract}

Keyword: Higher learning institution (HLI); Mobile application; Outcome-based education (OBE); System model; Teaching and learning 